\title{
Fluidized bed chemical vapor deposition synthesis of carbon nanotubes using different Fe-Co/Alumina catalytic powders
}

\begin{abstract}
Catalytic particles, Iron-Cobalt supported on Alumina, with different metal compositions were investigated in fluidized bed chemical vapor deposition of Ethanol at $600^{\circ} \mathrm{C}$ to produce carbon nanotubes (CNTs). The characteristics of catalytic particles as well as product were studied using different analytical techniques. Results indicated that the dispersion of metallic nanoparticles was higher when small amounts of two kinds of metal were used. However, lowering of metal content was not always favored with respect to process efficiency. This study proved atomic ratio of the active metals in bimetallic catalyst is not an accurate specification, and mass ratio of the metals should be considered. Also, it was demonstrated that the characteristics of catalytic particles, such as pore structure and their size as well as distribution of the metallic nanoparticles, need to be suitably modified to get the desired quality and quantity of CNTs.
\end{abstract}

Keyword: Catalytic particles; Chemical vapor deposition; CNT; Fluidized bed; Synthesis 